\title{
Effect of Clostridium difficile toxin A on human intestinal epithelial cells: induction of interleukin 8 production and apoptosis after cell detachment
}

\author{
Y R Mahida, S Makh, S Hyde, T Gray, S P Borriello
}

\begin{abstract}
Clostridium difficile is the aetiological agent of pseudomembranous colitis, and animal studies suggest the essential role of secreted toxin $A$ in inducing disease. This study examined the biological responses to toxin $A$ by human intestinal epithelial cells. Confluent monolayers of Caco2, HT29, and T84 cells and primary epithelial cells in organ cultures of human colonic biopsy specimens and after detachment with EDTA were studied. Interleukin 8 was assayed using enzyme linked immunosorbent assay (ELISA). Purified C difficile toxin A induced cell rounding and detachment of monolayers of the epithelial cell lines. Cells in detached monolayers initially remained viable while adherent to each other. Subsequently, an increasing number of apoptotic cells appeared in suspension. Exposure to toxin A for 24 hours induced interleukin 8 production in T84 and HT29 cells. Toxin A also induced epithelial cell rounding, detachment, and apoptosis in organ cultures of human colonic biopsy specimens. During culture (in medium only), EDTA detached colonic epithelial cells produced interleukin 8 and cell death occurred by apoptosis. Colonic disease by $C$ difficile may be initiated by toxin $A$ mediated induction of epithelial cell interleukin 8 production and apoptosis after cell detachment from the basement membrane. Studies on isolated (toxin untreated) colonic epithelial cells suggest that interleukin 8 production and apoptosis occur as a consequence of cell injury and detachment.

(Gut 1996; 38: 337-347)
\end{abstract}

Keywords: Clostridium difficile, toxin A, epithelial cells, apoptosis, interleukin 8.

University Hospital

Centre, Nottingham

Institute of Infection and Immunity,

University Hospital, Queen's Medical

Centre, Nottingham

Y R Mahida

S Makh

$S$ Hyde

S P Borriello

Correspondence to: Dr Y R Mahida, Division of Gastroenterology, University Hospital, Queen's Medical Centre, Nottingham NG7 2UH.

Accepted for publication 23 October 1995 cells, of which polymorphonuclear cells covering the mucosa is a characteristic feature of the disease and comprises polymorphonuclear cells, sloughed epithelial cells, mucin, and fibrin. Many cases of antibiotic associated pseudomembranes, are also caused by this diarrhoea, in the absence of detectable pathogen, which is the most common identifiable bacterial cause of nosocomial diarrhoea.

Intestinal disease follows infection with toxigenic $C$ difficile, which produces two toxins, $\mathrm{A}$ and B. ${ }^{4}$ Both toxins are large molecular weight proteins of approximately $300 \mathrm{kDa}$ and $270 \mathrm{kDa}$ respectively (based on the deduced amino acid sequence). They seem to exist as dimers as the molecular weights estimated from column chromatographic techniques are about $600 \mathrm{kDa}$ for toxin $\mathrm{A}$ and about $500 \mathrm{kDa}$ for toxin $\mathrm{B}$. Toxin agglutinates rabbit erythrocytes at $4^{\circ} \mathrm{C},{ }^{5}$ and binds bovine thyroglobulin $^{6}$ after interaction with the trisaccharide Gala $\alpha 1-3 \mathrm{Gal} \beta 1-4 \mathrm{GlcNAc}$. This property is exploited for purification of the toxin by affinity chromatography. ${ }^{6}$ Also, cells expressing large amounts of the trisaccharide receptor are more susceptible to the cytopathic activity of toxin A. ${ }^{7}$

Although toxin B has potent cytotoxic activity on cell lines in vitro, experiments in -animals suggest that it is toxin A that is essential for the induction of intestinal disease. Thus injection of purified toxin $A$, but not toxin $\mathrm{B}$, into rabbit ileal and colonic loops has been shown to induce pronounced intestinal inflammation. ${ }^{89}$ It has also been shown that intragastric administration of purified toxin A to hamsters induces intestinal inflammation. ${ }^{10}$ In the second of these studies, purified toxin A by itself did not induce intestinal disease unless there was prior derangement of the epithelial barrier. To initiate disease in humans, the first host cells that $C$ difficile toxin A would interact with are the colonic epithelial cells. These toxin-epithelial cell interactions probably represent the early, initiating events that subsequently lead to the severe colonic inflammation seen in pseudomembranous colitis. We have therefore examined the biological responses to $C$ difficile toxin $\mathrm{A}$ by the human colonic epithelial cell lines Caco-2, T84, and HT-29. In addition to morphological changes, the induction of interleukin 8 (IL8; a potent chemoattractant for polymorphonuclear cells) production in response to toxin A was also investigated. Confluent Caco-2 and T84 cells have many phenotype and functional characteristics of mature enterocytes and colonic crypt cells respectively. ${ }^{11} 12$ To relate the responses by the cell lines to those occurring in vivo, we also examined responses by primary epithelial cells in organ cultures of human colonic biopsy specimens. 


\section{Methods}

Purification of toxin $A$

Toxin A (free of even trace contamination with toxin B) was purified as described in detail previously. ${ }^{13}$ Briefly, toxigenic $C$ difficile (strain VPI 10463) was cultured in dialysis tubing and culture filtrates subsequently subjected to thyroglobulin affinity chromatography and two sequential anion exchange chromatographic steps with Q Sepharose FF (Pharmacia Biotech, Brussels, Belgium) and Mono Q (Pharmacia Biotech, Brussels, Belgium) columns, incorporated into a fast protein liquid chromatography apparatus (Pharmacia Biotech, Brussels, Belgium). Fractions were tested for cytotoxicity (as assessed by rounding of Vero cells) and haemagglutinating activity (using $1 \%$ rabbit erythrocyte suspension) as described in detail previously. ${ }^{13}$ Aliquots of the toxin were frozen at $-70^{\circ} \mathrm{C}$ and used for experiments within four weeks (no loss of cytotoxic activity occurred over this period). The concentration of the toxin obtained was about 50 to $100 \mu \mathrm{g} / \mathrm{ml}$ (protein quantitation by Bradford method; ${ }^{14}$ ). Where appropriate, the buffer $(0.4 \mathrm{mmol} / 1 \mathrm{NaCl}$ in $20 \mathrm{mmol} / \mathrm{TRIS}$, $\mathrm{pH} 7.5$ ) in which the toxin was suspended was used as control.

\section{Cell culture}

Caco-2, T84, and HT-29 cell lines were obtained from the European Collection of Animal Cell Cultures (Porton Down, UK). Caco-2 cells were cultured at $37^{\circ} \mathrm{C}$ in $5 \% \mathrm{CO}_{2}$ in Dulbecco's minimal essential medium (DMEM; Gibco BRL, Gaithersburg, MD) containing 10\% fetal calf serum (FCS; Gibco BRL, Gaithersburg, MD), $10 \mu \mathrm{g} / \mathrm{ml}$ transferrin (Sigma Chemical, St Louis, MO), 2 $\mathrm{mmol} / \mathrm{I}$ glutamine (Sigma Chemical, St Louis, MO), $100 \mathrm{U} / \mathrm{ml}$ penicillin G (Britannia Pharmaceuticals, Surrey, UK), and $0.1 \mathrm{mg} / \mathrm{ml}$ streptomycin (Evans Medical, Surrey, UK). Monolayers of Caco-2 cells (passage 37-42) were used at three weeks after confluency. By this time the cells had developed dome regions and expressed microvilli as well as sucrase isomaltase activity (determined using assay from Sigma Chemical, St Louis, MO). T84 cells (passage 68-74) were grown in 50\% DMEM, 50\% Ham's F12 medium (Gibco BRL, Gaithersburg, $M D$ ), supplemented with $10 \% \mathrm{FCS}, 2 \mathrm{mmol} / \mathrm{l}$ glutamine, and antibiotics (as for Caco-2 cells). HT29 cells (parental type; passage 132-4) were cultured in DMEM supplemented with $10 \% \mathrm{FCS}, 2 \mathrm{mmol} / \mathrm{l}$ glutamine, and antibiotics (as for the above cell lines). T84 and HT-29 cells were grown to confluency for the studies with toxin A.

For morphological studies by phase contrast microscopy, the cells were grown to confluency in 24 well tissue culture plates (Nunc, Gibco BRL, Gaithersburg, MD) and toxin A added to different final concentrations. Morphological changes were assessed over the next 96 hours using an Olympus CK2 inverted microscope.

Studies of trypan blue (Sigma Chemical, St Louis, MO) uptake were performed after adding the dye to a final concentration of $0.01 \%$. After culture for one hour, the proportion of cells that had taken up the dye was determined by counting at least 200 cells per well. Nuclear morphology of epithelial cells after staining with acridine orange (final concentration of $4 \mu \mathrm{g} / \mathrm{ml}$; Sigma Chemical, St Louis, MO) was examined under a fluorescent microscope equipped with fluorescein filters and dichroic mirrors (Nikon Diaphot 300).

For studies by electron microscopy, the epithelial cells were grown to confluency on sterile Thermanox coverslips (Nunc, Gibco BRL, Gaithersburg, MD) before applying toxin $\mathrm{A}$. The coverslips were subsequently fixed and processed as described later. Cells that had become detached were also harvested and processed for electron microscopy (see later).

\section{Assay for mitochondrial dehydrogenase}

In this assay, metabolism by mitochondrial dehydrogenase of the yellow tetrazolium salt, 3-(4,5-dimethylthiazol-2-yl)-2,5-diphenyl tetrazolium bromide (MTT) to the purple formazan reaction product can be quantified spectrophotometrically. Such assays have been used to measure cell proliferation and cytotoxicity without the use of radioisotopes. ${ }^{15}$

The cells were grown to confluency in 96 well tissue culture plates (Nunc, Gibco BRL, Gaithersburg, MD) and the assays were performed in quadruplicate. After culture with toxin A for varying time periods, MTT (Sigma Chemical, St Louis, MD) was added (to final concentration of $0.5 \mathrm{mg} / \mathrm{ml}$ ) to each well and incubation continued for four hours. After the addition of $100 \mu \mathrm{l}$ of solubilisation solution (5\% sodium dodecyl sulphate in $0.1 \mathrm{mmol} / 1$ $\mathrm{HCl}$ ) the plates were incubated overnight in a cell culture incubator. Spectrophotometric absorbance of the samples was subsequently carried out with a microtitre enzyme linked immunosorbent assay (ELISA) plate reader using $570 \mathrm{~nm}$ filter.

\section{Organ culture of colonic biopsy specimens}

Colonic biopsy specimens were obtained from patients undergoing colonoscopy for clinical indications (surveillance for polyps, investigation for occult bleeding, and changed bowel habit). In addition to tissues for routine histological examination (which were all confirmed to be normal) additional samples were taken from the sigmoid colon for organ culture studies. These studies were approved by the ethics committee of Queen's Medical Centre and the additional specimens were only obtained after informed consent.

Organ cultures were performed as previously described. ${ }^{16}$ The samples were placed immediately in RPMI (Gibco BRL, Gaithersburg, MD) containing 10\% FCS. They were subsequently placed, within five minutes of removal, on a stainless steel mesh over a culture dish (Falcon, Becton Dickinson, Lincoln, NJ) containing pre-warmed medium (10\% FCS/RPMI) and C difficile toxin A at 
final concentrations of $1 \mathrm{pg} / \mathrm{ml}$ to $1000 \mathrm{ng} / \mathrm{ml}$ (or the same volume of control buffer). The culture dishes were placed in a sealed chamber and equilibrated with $95 \% 0_{2} / 5 \% \quad \mathrm{CO}_{2}$ and incubated at $37^{\circ} \mathrm{C}$. After varying time intervals (30 minutes to 24 hours), the specimens were placed in either $0.9 \% \mathrm{NaCl}$ containing $10 \%$ formalin (for routine histological examination) or fixative for electron microscopy (see later). In some studies, cells that had become detached from the specimens were collected and processed for electron microscopy (see later).

\section{Isolation and culture of primary colonic epithelial cells}

Colonic epithelial cells were isolated from fresh operation resection specimens (seven) as previously described. ${ }^{17}$ Normal mucosa (at least $5 \mathrm{~cm}$ from tumour) was placed in RPMI (at $4^{\circ} \mathrm{C}$ ) within 10 minutes of colonic resection. Epithelial cells were obtained by incubating mucosal strips in Hank's balanced salt solution without calcium and magnesium (HBSS; Gibco BRL, Gaithersburg, MD) containing $1 \mathrm{mmol} / 1$ EDTA (Sigma Chemical, St Louis, $\mathrm{MD})$. The incubations were performed for two 30 minute periods in a shaking water bath at $37^{\circ} \mathrm{C}$. The detached epithelial cells (containing surface and crypt cells) were pooled and washed twice with HBSS before culture in $10 \% \mathrm{FCS} / \mathrm{RPMI}$ at concentration of $1 \times 10^{6} / \mathrm{ml}$ or $5 \times 10^{6} / \mathrm{ml}$. The cultured cells were used for morphological studies by transmission electron microscopy (TEM), studies of DNA degradation, and of IL8 production (see later).

\section{Electron microscopy}

After organ culture, colonic biopsy specimens were immersed in $2.5 \%$ gluteraldehyde (in $0 \cdot 1 \mathrm{M}$ cacodylate buffer, $\mathrm{pH} 7 \cdot 4$ ) for two hours. Tissue slices (1-2 mm thick) were further fixed for 12 hours. Epithelial monolayers on coverslips and cells in suspension (those detached from toxin A treated monolayers and biopsy tissues in organ culture as well as isolated primary colonocytes) were fixed in the above fixative for two hours. The cells in suspension were centrifuged at $600 \times g$ for 10 minutes. After washing, the cell pellets were recentrifuged in plasma and fixed for a further four hours before cutting into $1 \mathrm{~mm}$ cubes. All the samples were subsequently washed in phosphate buffered saline (PBS) and post-fixed in $1 \%$ osmium tetroxide for one hour before dehydrating in ethanol and embedding in Epon resin, according to standard procedures. ${ }^{18}$ Suitable areas for TEM were selected from $0.5 \mu \mathrm{m}$ toluidine blue stained sections. They were stained with uranyl acetate and lead citrate, before being observed in a Jeol 1200 EX transmission electron microscope.

\section{Analysis of DNA degradation}

The studies of DNA fragmentation were performed by modification of a previously described technique. ${ }^{19}$ EDTA detached colonic epithelial cells were cultured in $10 \%$ FCS/RPMI at a concentration of $5 \times 10^{6} / \mathrm{ml}$ for two hours to 24 hours. After centrifugation, the cells were resuspended in lysis buffer (10 $\mathrm{mmol} / 1 \mathrm{TRIS}, 1 \mathrm{mmol} / \mathrm{EDTA}(\mathrm{pH} 7 \cdot 5)$ containing $0 \cdot 2 \%$ Triton $\mathrm{X}-100$ ) and incubated at room temperature for 10 minutes. The lysates were centrifuged at $13000 \times \mathrm{g}$ for 10 minutes and the supernatant (containing fragmented DNA) was incubated overnight, at $37^{\circ} \mathrm{C}$ with proteinase $\mathrm{K}$ (final concentration $0.1 \mathrm{mg} / \mathrm{ml}$; Boehringer Mannheim, Lewes, UK). After phenol-chloroform extraction twice and ethanol precipitation, the DNA was incubated for one hour at $37^{\circ} \mathrm{C}$ with $50 \mu \mathrm{g} / \mathrm{ml} \mathrm{RNAse} \mathrm{A.}$ DNA was subsequently analysed on a $1 \%$ agarose gel.

\section{Assay of IL8}

IL8 production by epithelial cell lines and EDTA detached primary colonic epithelial cells was studied. The epithelial cell lines were grown to confluency (as described above) in 24 well plates and cells washed three times with warm medium before culture in the presence of different concentration of toxin A (10-1000 $\mathrm{ng} / \mathrm{ml}$ ). After 24 hours, supernatants were collected and the cells (still adherent to the plates) gently washed before culture for a further 24 hours in fresh medium (in the absence of toxin A). Supernatants were centrifuged at $10000 \times \mathrm{g}$, at room temperature, for 10 minutes and aliquots stored at $-70^{\circ} \mathrm{C}$.

Primary colonic epithelial cells were cultured (in $10 \% \mathrm{FCS} / \mathrm{RPMI}$ only) at a concentration of $5 \times 10^{6} / \mathrm{ml}$ for three hours and 24 hours. After centrifugation $(10000 \times g$ at room temperature), supernatants and cell pellets were collected. The cell pellets were resuspended in $1 \mathrm{ml} \mathrm{10 \%} \mathrm{FCS/RPMI} \mathrm{and} \mathrm{cells}$ lysed by three freeze/thaw cycles. Aliquots of supernatants and lysates were stored at $-70^{\circ} \mathrm{C}$.

IL8 was assayed using a sandwich ELISA ( $R$ and D Systems, Minneapolis, $M N$ ). The inter and intra-assay variation for this assay in our laboratory was less than $12 \%$. Initial studies showed that neither toxin A (at concentrations of up to $1000 \mathrm{ng} / \mathrm{ml}$ ), nor the culture media used, interfere with the detection of IL8.

\section{Statistical analysis}

Data were analysed by one way analysis of variance and Student's $t$ test.

\section{Results}

EFFECT OF C DIFFICILE TOXIN A ON INTESTINAL EPITHELIAL CELL LINES

In the studies described below, initial experiments showed no significant differences in the responses by cells cultured in medium only compared with those cultured in medium containing control buffer (used in volumes similar to those for toxin A). Therefore in all subsequent experiments with the epithelial cells lines, cell culture medium only was used as 

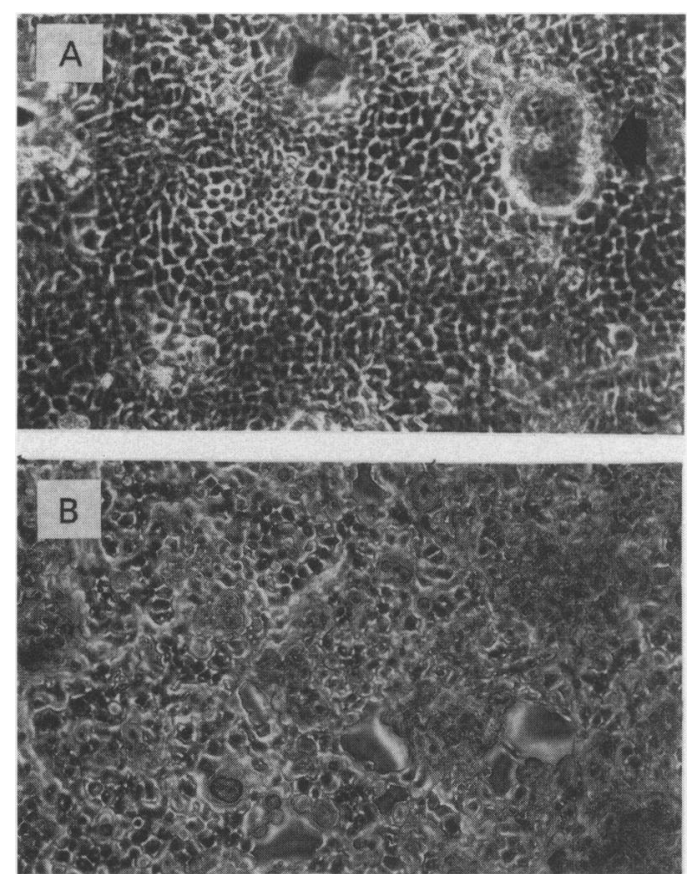

Figure 1: Phase contrast photomicrograph of $(A)$ control and (B) toxin $A$ exposed (1000 $\mathrm{ng} / \mathrm{ml}$ for 24 hours) Caco-2 monolayers. Caco-2 cells were cultured for three weeks after confluency before exposure to toxin A. Closely apposed polygonal cells are seen in the control monolayer, which also contains a dome region (arrow). Toxin $A$ exposed monolayer shows cell rounding and focal loss of cell-cell contacts. Not evident from the Figure is the fact that a significant proportion of the monolayer has also become detached from the bottom of the culture plate by this time.

control for the studies examining responses to $C$ difficile toxin A.

\section{Morphological changes}

Studies by phase contrast microscopy showed that $C$ difficile toxin $\mathrm{A}$ induced cell rounding in

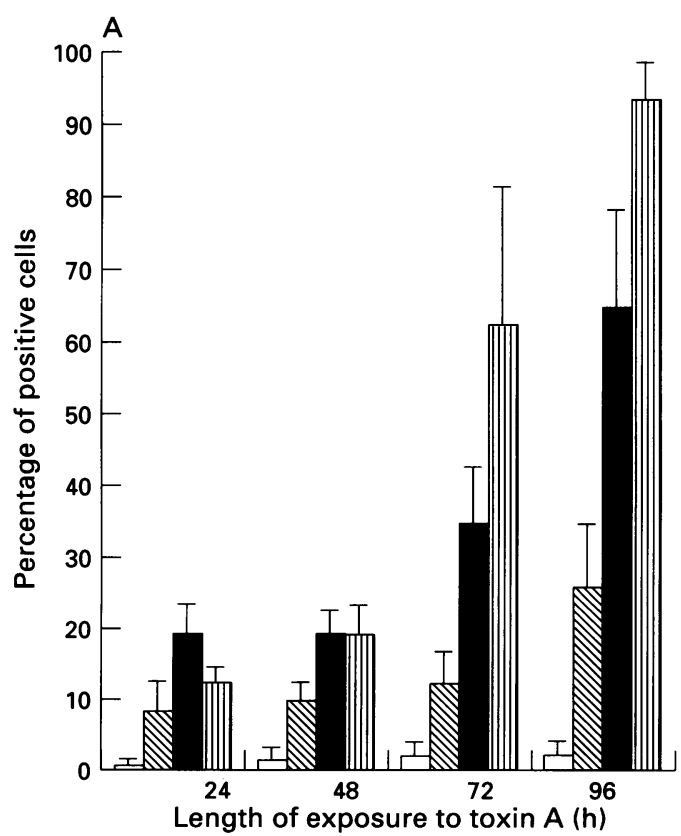

each of the three cell lines studied. The time course over which the changes occurred was dependent upon the cell type studied as well as the concentration of the toxin present in the culture medium.

The earliest morphological changes occurred at concentrations of toxin A of 100 $\mathrm{ng} / \mathrm{ml}$ or greater (up to $1000 \mathrm{ng} / \mathrm{ml}$ ) with cell rounding within the first six hours in Caco-2 and HT-29 cells and at 24 hours in T84 cells. At lower concentrations of the toxin, rounding of all the cells was seen in Caco-2 and HT-29 monolayers at 24 hours. Caco-2 (Fig 1) and T84 cells were subsequently studied in more detail. The rounded epithelial cells subsequently began to detach from the bottom of the culture dish while remaining adherent to each other. At concentrations of toxin A of 100 $\mathrm{ng} / \mathrm{ml}$ or greater, $50 \%$ or more of the Caco-2 monolayer became detached at 24 hours, and usually by 48 hours the monolayer had become completely detached from the culture dish. In T84 monolayers, cell detachment from the culture dishes was not apparent until after 48 hours of exposure to the toxin. Cells within the detached monolayers initially remained adherent to each other. Subsequently, floating individual cells, smaller in size than those adherent to each other, appeared in increasing numbers with time.

When viewed by phase contrast microscopy, cells that had become detached from the culture dish seemed to be healthy while adherent to each other. To confirm viability, the ability of the cells to exclude the dye trypan blue (uptake of the dye being indicative of loss of membrane integrity) was studied. More than $90 \%$ of cells in detached Caco-2 and T84 monolayers excluded the dye while adherent to each other, whereas the single cells

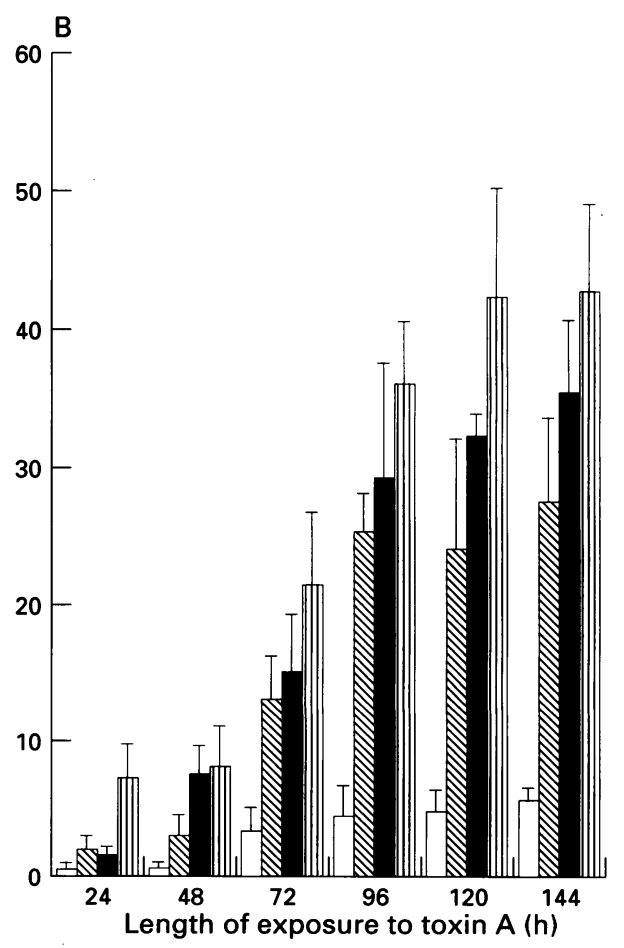




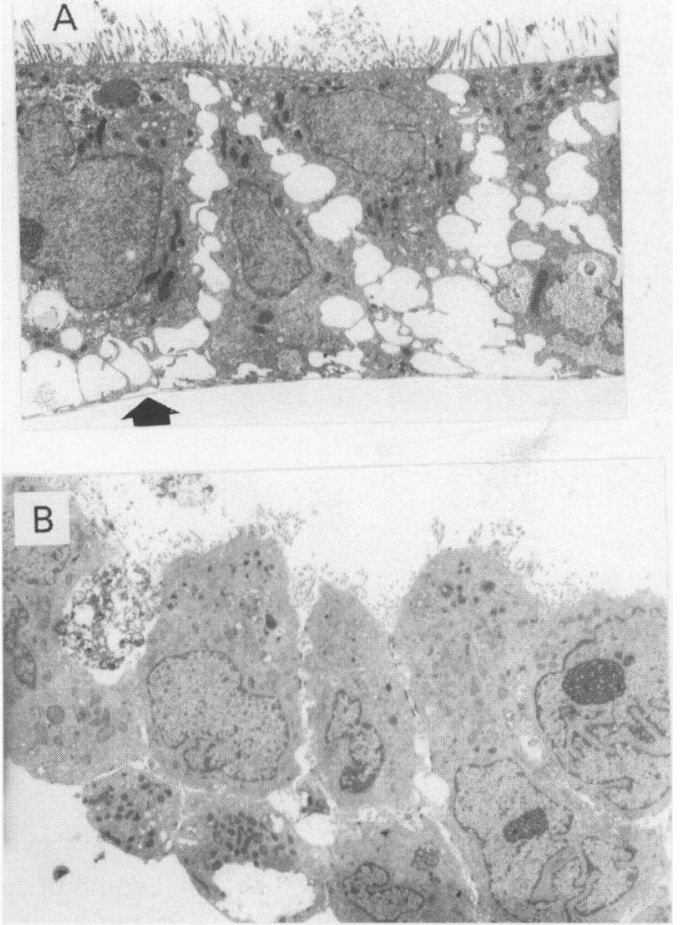

Figure 3: Transmission electron micrograph of $(A)$ control and $(B)$ toxin $A$ exposed (1000 $\mathrm{ng} / \mathrm{ml}$ for 24 hours) Caco-2 monolayers. Caco-2 cells were cultured for three weeks after confluency on Thermanox coverslips before exposure to toxin $A$. Cells in the control monolayer are adherent to the coverslip (arrow) and to each other and express microvilli. Cells in the toxin $A$ exposed monolayer are detached from the coverslip but remain adherent to each other and appear viable.

in suspension (which were smaller) did not. The numbers of single, detached, (trypan blue positive) cells increased progressively in both a time and dose dependent fashion, this being more rapid for Caco-2 than T84 cells (Fig 2A and B).

Studies by TEM were carried out to investigate ultrastructural changes in epithelial cells in response to toxin $A$ and were also used to study the type of cell death that eventually
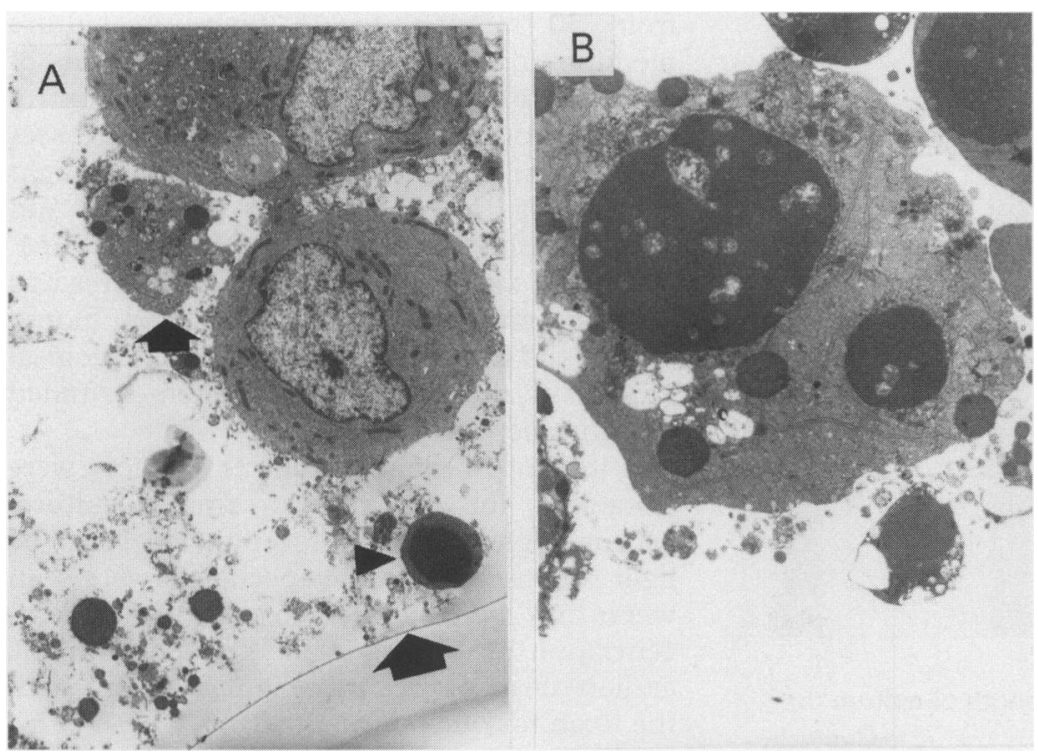

Figure 4: Transmission electron micrographs of T84 cells grown to confluency on a Thermanox coverslip and then exposed to $\mathrm{C}$ difficile toxin $A$ for 72 hours. In $(A)$, the cells are detached from the coverslip (large arrow) but the two cells adherent to each other appear viable. A cell undergoing apoptosis (small arrow) and a membrane bound apoptotic body (arrowhead) are also present. In (B) apoptotic cells are seen with nuclear fragmentation into discrete spherical structures. occurred. For these experiments, the epithelial cells were grown to confluency on Thermanox cover slips. Morphologically these cells looked similar to those grown in tissue culture plates and their responses to toxin A (as studied by phase contrast microscopy) were also similar.

TEM studies confirmed the finding by phase contrast microscopy of cell rounding and detachment of monolayers in response to toxin A. In keeping with the findings above, cells in the detached monolayers ultrastructurally appeared viable while adherent to each other (Fig 3A and B). Studiets over the subsequent time period showed that the increasing number of smaller, individual cells in suspension were undergoing apoptosis (Fig 4A and B). In these cells the nuclei were characteristically broken into discrete spherical structures containing dense chromatin while retaining integrity of the cell membrane and many cytoplasmic organelles. Subsequently the cells were broken into discrete membrane bound apoptotic bodies with eventual complete disintegration into cellular debris. In studies in both cell lines over a number of days, cells at different stages of apoptosis were seen together with viable looking cells (these always adherent to other cells) suggesting that programmed cell death in individual cells was occurring at different time points and seemed to occur as cells were detaching from adjacent cells. These findings were confirmed by staining toxin A exposed cells with acridine orange (and examination under a fluorescent microscope) when fluorescent fragments of nuclei were seen in apoptotic cells. In Caco-2 and T84 monolayers, apoptotic cells were prominent from 48 hours and 72 hours respectively of exposure to toxin A (at $100 \mathrm{ng} / \mathrm{ml}$ or greater). Cell death by necrosis was not seen at any stage.

Changes in mitochondrial dehydrogenase activity To determine the effect of toxin $A$ on cell metabolic activity, cellular mitochondrial dehydrogenase activity was assessed using the MTT assay. Such assays are often used to confirm cell survival and growth. In Caco-2 monolayers exposed to toxin A for 24 hours, mitochondrial dehydrogenase activity was not significantly different from control medium. The subsequent fall in the mitochondrial enzyme activity occurred in a dose dependent fashion (Fig 5A). For T84 cells, there was a significant $(p<0.01)$ increase in mitochondrial dehydrogenase activity after 24 hours of exposure to toxin A (Fig 5B). A significant $(p<0.01)$ fall in the mitochondrial enzyme activity only occurred after 96 hours of exposure to the highest concentration of the toxin $(1000 \mathrm{ng} / \mathrm{ml})$. As for the studies with trypan blue (above), MTT studies also showed greater sensitivity of Caco-2 cells to toxin A compared with T84 cells.

\section{Effect on IL8 production}

To investigate whether the toxin injured epithelial cells were able to produce molecules 

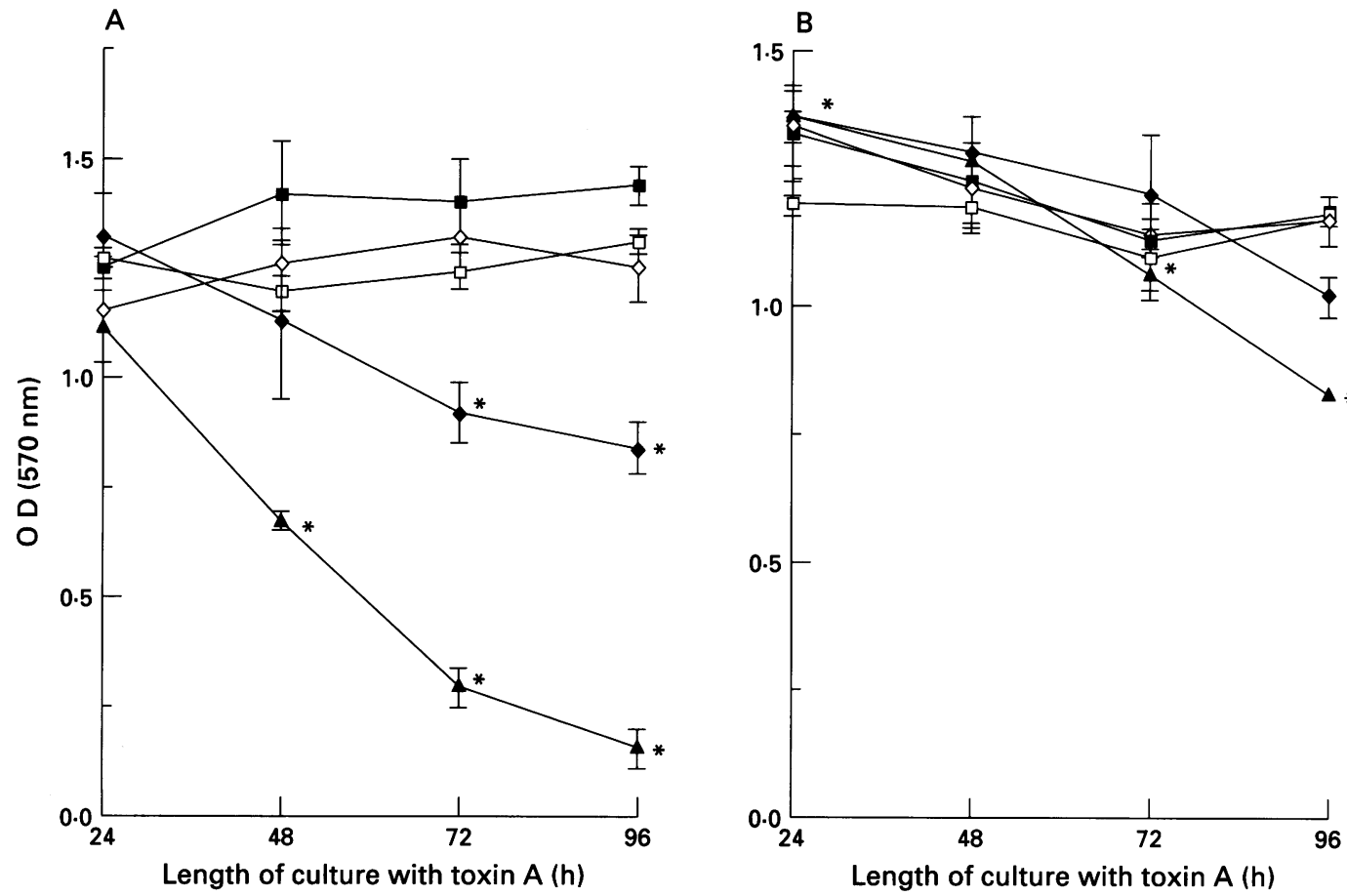

Figure 5: MTT assays on (A) Caco-2 and (B) T84 monolayers exposed to $\mathrm{C}$ difficile toxin $A$. Confluent monolayers of Caco-2 and T84 cells (grown in 96 well plates) were cultured in control medium only ( $\square$ ) or in the presence of $1 \mathrm{ng} / \mathrm{ml}$ (), $10 \mathrm{ng} / \mathrm{ml}(\diamond), 100 \mathrm{ng} / \mathrm{ml}(\diamond)$, or $1000 \mathrm{ng} / \mathrm{ml}(\mathbf{\Delta})$ toxin A. After culture for varying time periods, MTT assays (which reflect cellular mitochondrial dehydrogenase activity) were performed. Assays were performed in quadruplicate and data points represent mean (SD). For each cell line, the figure is representative of three separate experiments. ${ }^{{ }^{*}} p<0.01$ compared with medium only.

capable of initiating an inflammatory response, production of the potent polymorphonuclear chemoattractant IL8 was studied. During the first 24 hours of exposure to toxin A (at concentrations of 10 to $1000 \mathrm{ng} / \mathrm{ml}$ ), IL8 production was induced in T84 and HT-29 cells (Fig $6 \mathrm{~A}$ and $\mathrm{B}$ respectively). There was no induc-

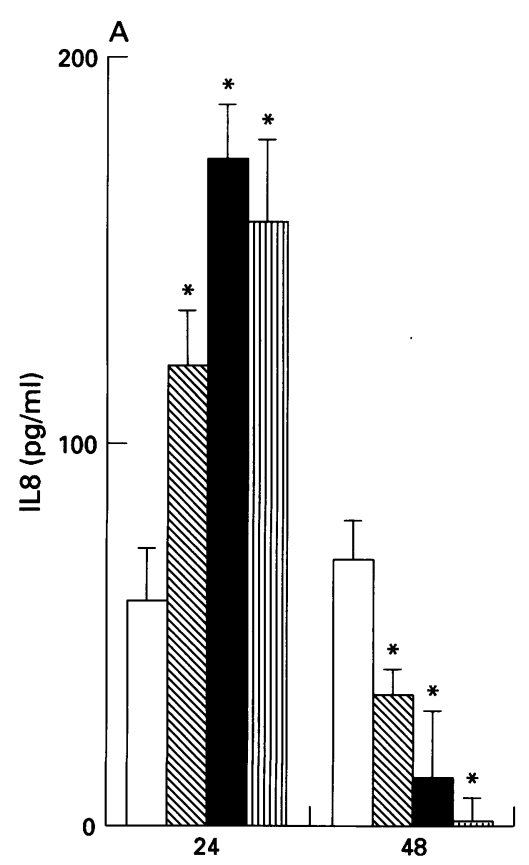

Length of culture ( $h$ )

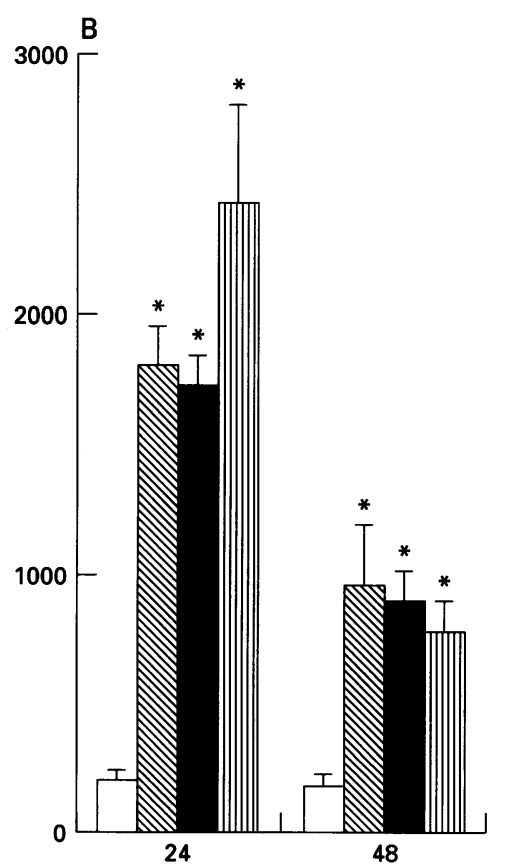

Length of culture (h)
Figure 6: IL8 production by (A) T84 and (B) HT29 monolayers exposed to C difficile toxin $A$. Confluent monolayers of the cells (in 24 well plates) were washed with warm medium before culture in control medium only ( $\square$ ) or in the presence of $10 \mathrm{ng} / \mathrm{ml}$ (四), $100 \mathrm{ng} / \mathrm{ml}$ ( $)$, or $1000 \mathrm{ng} / \mathrm{ml}$ (而) toxin A. After 24 hours, supernates were collected for IL8 assays. The cells were then gently washed with warm medium before culture in medium only for a further 24 hours after which supernates were collected for IL8 assays. ${ }^{\star} p<0.01$ compared with medium only control. tion of IL8 production in the Caco-2 cells (data not shown).

\section{EFFECT OF C DIFFICILE TOXIN A ON HUMAN}

\section{COLONIC MUCOSA IN ORGAN CULTURE}

\section{Morphological changes}

To discover if the responses to $C$ difficile toxin A by colon carcinoma derived cell lines reflect those likely to occur in vivo, primary human colon epithelial cells were studied in organ culture of colonic biopsy specimens. The specimens were cultured for varying periods of time from 30 minutes to 24 hours in culture medium containing varying concentrations of toxin A (from $1 \mathrm{pg} / \mathrm{ml}-1000 \mathrm{ng} / \mathrm{ml}$ ) or control buffer. Morphological changes in tissue sections of the specimens were assessed by light microscopy (in haematoxylin and eosin and toluidine blue stained sections) and by TEM. The effect of toxin $\mathrm{A}$ in the organ cultures was only investigated where the control biopsy sample did not show significant morphological changes to the epithelial cells when examined by light microscopy.

A total of 74 samples from 21 subjects, were suitable for analysis after culture. Morphological changes to epithelial cells (by light microscopy) in the specimens were seen when they were exposed to toxin A at a concentration of $100 \mathrm{ng} / \mathrm{ml}$ or greater, with the earliest changes occurring after culture with the toxin for one hour.

No morphological changes were seen in mucosal tissue from one of five subjects whose specimens had been exposed to toxin $\mathrm{A}$ at a concentration of $1000 \mathrm{ng} / \mathrm{ml}$ for 24 hours. Samples from this 'non-responder' had also 

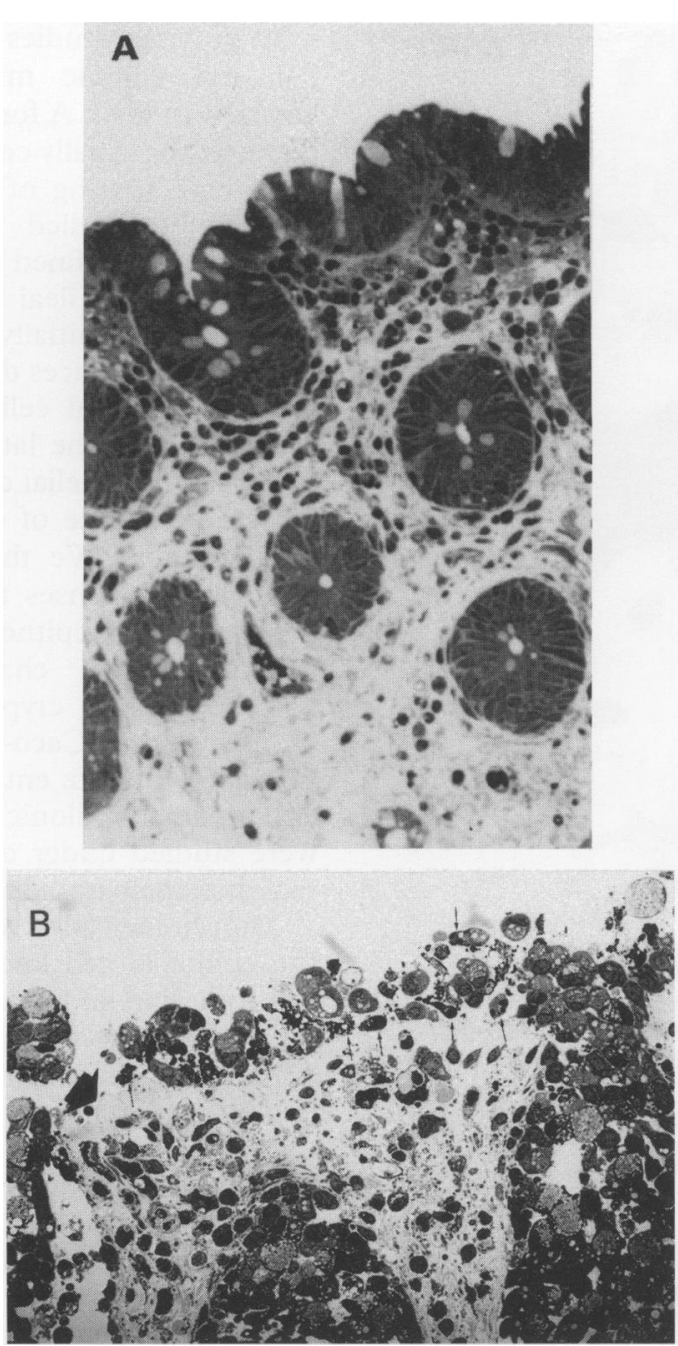

Figure 7: Photomicrographs of toluidine blue stained sections of $(A)$ control and $(B)$ toxin $A$ exposed

(1000 $\mathrm{ng} / \mathrm{ml}$ ) colonic biopsy specimens in organ culture for 24 hours. There is preservation of epithelial integrity in the control biopsy sample. In the toxin exposed specimen, the epithelial cells are round and most have become detached from the basement membrane (large arrow) and from each other. $A$ number of epithelial cells are also undergoing apoptosis (small arrows show some of these cells).

been exposed to lower concentrations of the toxin $(10 \mathrm{ng} / \mathrm{ml}$ and $100 \mathrm{ng} / \mathrm{ml})$ without any morphological changes (when compared with control). The preparation of toxin A used for this 'non-responder' was biologically active in organ cultures from other subjects, as well as on epithelial cell lines.

Where toxin $\mathrm{A}$ had an effect in the organ cultures, the earliest morphological changes were seen in the surface epithelial cells, with cell rounding and detachment from the basement membrane. These changes were first seen after exposure to the toxin for one hour, the crypt cells were not usually affected at this stage. By 24 hours, however, both surface and crypt cells were affected and a number of smaller apoptotic cells were seen by light microscopy (Fig 7A and B).

TEM studies of control 24 hour organ cultures (in medium with control buffer only) often showed ultrastructural changes in some epithelial cells, characterised by cell processes (Fig 8A). However, these epithelial cells remained adherent to the basement membrane and to each other, and appeared viable ultrastructurally. TEM studies of organ culture biopsy specimens affected by toxin A confirmed epithelial cell rounding and detachment from the basement membrane. In many instances the detached cells remained adherent to each other (as for the studies with the cell lines), and ultrastructurally such cells appeared viable with intact mitochondria and endoplasmic reticulum (Fig 8B-D). Individual, detached epithelial cells were also seen, that had morphological features of cells undergoing apoptosis, especially in specimens exposed to toxin A for 24 hours.

In those studies where detached cells were also collected and studied by TEM, most showed features of apoptosis. In contrast with cells in monolayers, epithelial cells in toxin A exposed organ cultures often contained vacuoles of variable size.

\section{STUDIES ON NORMAL COLONIC EPITHELIAL CELLS DETACHED FROM THE BASEMENT MEMBRANE WITH EDTA}

\section{Morphological studies}

Apoptosis in the epithelial cell lines exposed to $C$ difficile toxin A could represent an inherent response of the cells to injury and detachment, or could be induced specifically by continued intracellular action of the toxin. To determine the probable sequence of events, epithelial cells were detached from the basement membrane of normal colonic mucosa by treatment with EDTA and cultured in the absence of toxin A. Subsequent studies by TEM showed that before culture, and after culture for three hours and 24 hours, a mean (SD) of $41 \cdot 5(2 \cdot 6) \%, 70$ $(14 \cdot 1) \%$, and $81(8) \%$ respectively of the cells showed morphological features of apoptosis (Fig 9), confirmed by their characteristic pattern of DNA degradation (Fig 10).

TEM studies on cultured epithelial cells also showed that the small number of viable cells present were larger than those undergoing apoptosis and were adherent to other viable cells.

\section{IL8 production by EDTA detached colonic epithelial cells}

The ability of EDTA detached epithelial cells to produce IL8 during culture (in the absence of toxin A) was also examined (Fig 11). Very little IL8 was detected in lysates of epithelial cells obtained soon after detachment (that is, not cultured). After culture for three hours, a large amount of IL8 was detected in the cell lysates, but considerably lower values in the supernatants. The converse was the case after culture for 24 hours suggesting that the cytokine had been released from the cells by this time.

\section{Discussion}

Animal studies have shown that $C$ difficile toxin A plays an essential part in inducing intestinal inflammation. ${ }^{8-10}$ Studies in hamsters using purified preparations of toxin $A$ and $B$, suggest that toxin $A$ is required to breach the epithelial barrier to allow toxin $B$ access into the mucosa to mediate its effects. ${ }^{10}$ Responses by colonic 


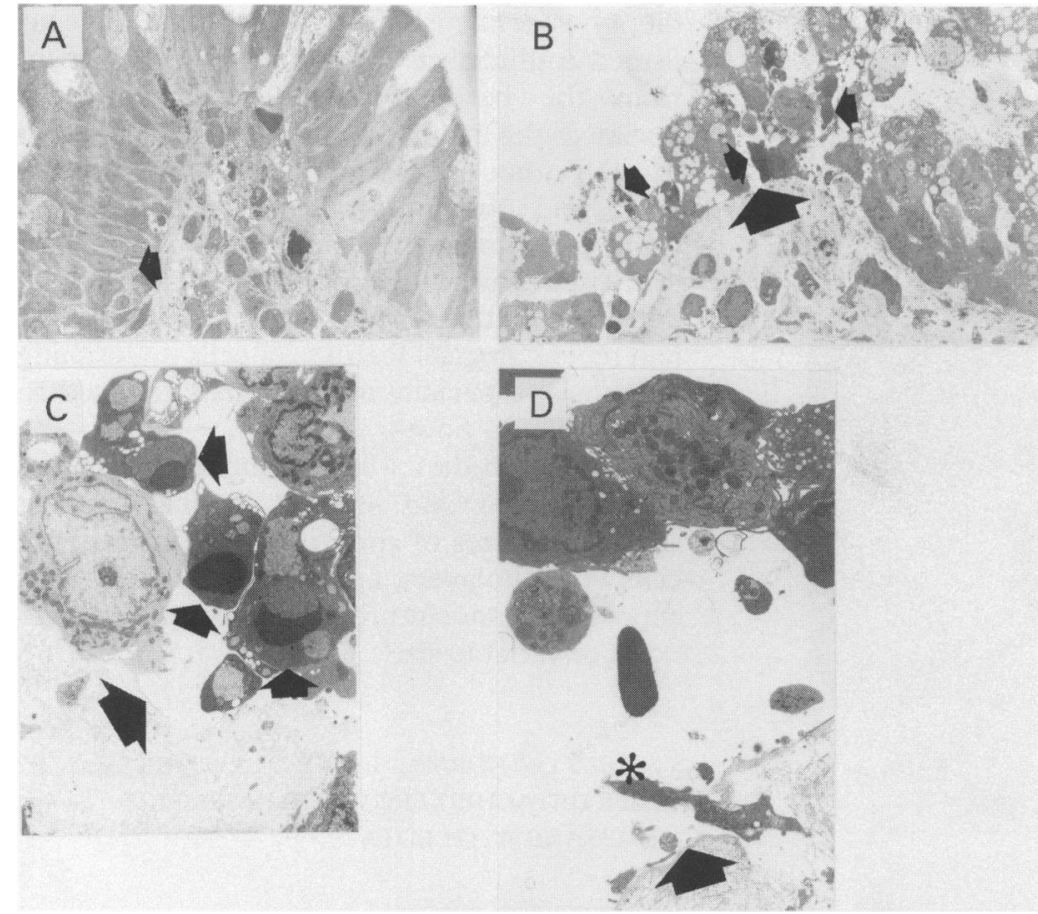

Figure 8: Transmission electron micrographs of $(A)$ control and $(B-D)$ toxin $A$ exposed (1000 ng/ml for 24 hours) colonic biopsy specimen. The control specimen shows preservation of epithelial integrity although some cells have processes (arrow) in their lateral aspects with some separation from neighbouring cells. In toxin $A$ exposed specimens $(B, C$, D) epithelial cells are round and many have become detached from the basement membrane (large arrow). Note also the presence of heterogeneous vacuolar structures in many affected cells (especially in B). Many basement membrane detached cells remain adherent to each other and appear viable. Cells undergoing apoptosis are also present (small arrows). Part of a cell ( ${ }^{\star}$; probably a macrophage) is seen to be migrating out of the lamina propria, via a basement membrane pore, in (D).

epithelial cells to toxin A may therefore represent early initiating events, which ultimately lead to severe intestinal inflammation commonly seen in patients with pseudomembranous colitis.

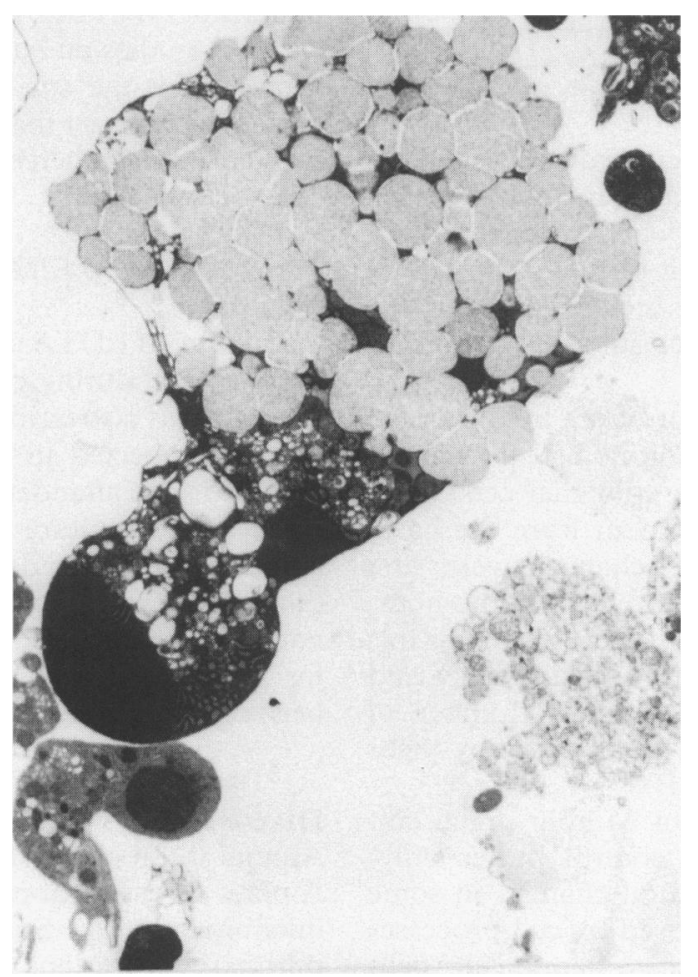

Figure 9: Transmission electron micrograph of three hour cultured, EDTA detached goblet cell. The cell is undergoing apoptosis; nucleus of the goblet cell is darker than that of a neighbouring cell (because it contains dense chromatin).
In previous studies where the small intestinal and colonic mucosa of animals was exposed to toxin A for a period of a few hours, damage was usually confined to mature enterocytes with sparing of crypts. ${ }^{2021}$ In addition, binding of labelled toxin $\mathrm{A}$ has also been shown to be confined largely to mature enterocytes of rabbit ileal explants. ${ }^{22}$ Our studies were therefore initially based on the hypothesis that toxin $\mathrm{A}$ induces damage to mature surface colonic epithelial cells with sparing of crypt cells, and that the latter respond to injury to the surface epithelial cells by producing IL 8 to initiate a cascade of events leading to severe inflammation. We therefore investigated the biological responses to $C$ difficile toxin $\mathrm{A}$ by human colonic epithelial cell lines that reflect the phenotypic characteristics of mature enterocytes and crypt cells. Thus confluent monolayers of Caco-2 cells were used as a model for mature enterocytes ${ }^{11}$ and T84 cells as a model for colonic crypt cells. ${ }^{12}$ HT29 cells were studied under conditions in which they remain largely undifferentiated.

Morphologically, responses of the cells in the epithelial cell lines were characterised by cell rounding and detachment from the extracellular matrix coating of the culture dish. These detached cells initially remained adherent to each other and were viable as shown by their ability to exclude the dye trypan blue and ultrastructural features. These cells were also shown to be metabolically active as assessed by mitochondrial dehydrogenase activity in the MTT assays.

Individual, smaller, detached cells, which were trypan blue positive subsequently began to appear in culture. Studies by TEM showed that these cells had characteristic features of cells undergoing apoptosis. ${ }^{23}$ Previous studies have shown that apoptotic cells are usually much smaller than on-apoptotic cells. ${ }^{24}$ Other features, which include breakdown of the nucleus into discrete spherical structures, followed by the formation of apoptotic bodies, ${ }^{25}$ were also seen. Caco- 2 cells were more sensitive to toxin A than T84 cells, as shown by earlier cell detachment and increase in the proportion of trypan blue positive cells, as well as an early fall in the mitochondrial dehydrogenase activity. The sequence of events induced by toxin A (in the confluent epithelial cell lines) of cell rounding, detachment of the monolayer, and subsequent cell death by apoptosis over a prolonged period of time has not been described previously.

To find out if the responses of these carcinoma derived cell lines reflect those of cells in vivo, primary epithelial cells in organ cultures of colonic biopsy specimens were also investigated. In specimens in which toxin $\mathrm{A}$ induced changes, responses by the primary epithelial cells were morphologically similar to those seen in the toxin exposed epithelial cell lines. Although they occurred over a shorter time period, the responses of the primary colonocytes were observed at similar concentrations of toxin $\mathrm{A}$ to those inducing analogous changes in the cell lines. The earliest morphological changes in the organ cultures were seen after 


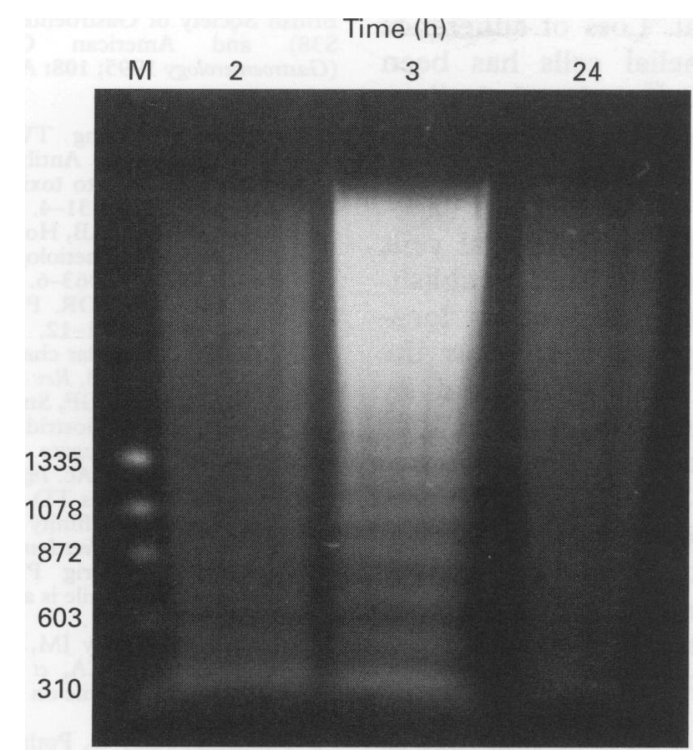

Figure 10: Agarose gel electrophoresis of DNA isolated from EDTA detached colonic epithelial cells cultured for two, three, and 24 hours (in medium only). DNA size markers are shown in base pairs on the left. Characteristic 'ladder' pattern is prominent in DNA isolated from two hour and three hour cultures.

one hour, with rounding of surface enterocytes and detachment from the basement membrane. Crypt cells were affected later when apoptotic cells were also seen. These findings, as well as the relative resistance of T84 cells (compared with Caco-2 cells), suggest that colonic crypt cells in vivo are more resistant to the effect of toxin A than the mature surface enterocytes. The relative resistance of the crypt cells may allow them time to respond to injury by producing cytokines such as IL8, as suggested by the ability of $\mathrm{T} 84$ cells to produce this cytokine in response to toxin $\mathrm{A}$.

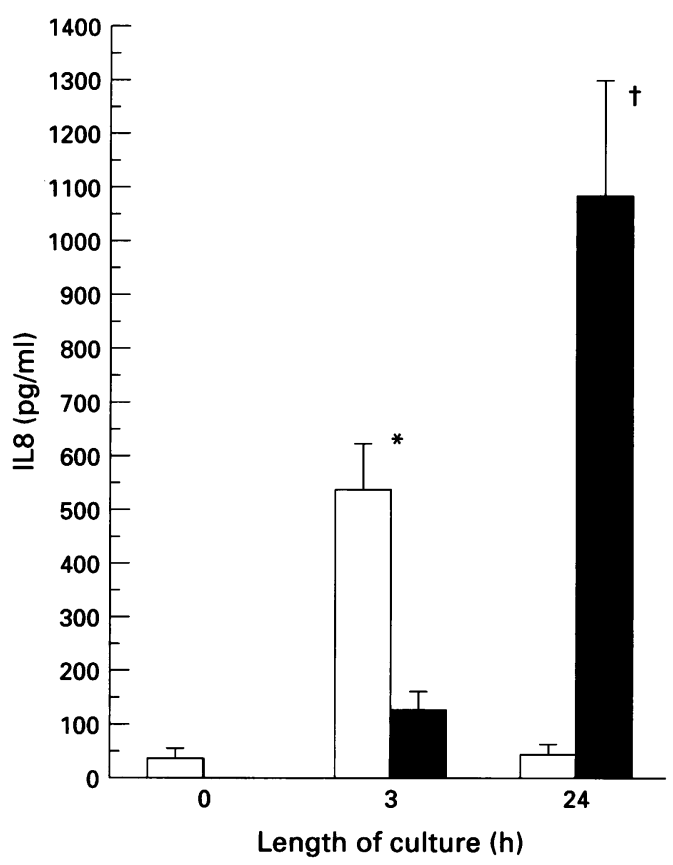

Figure 11: IL8 production by EDTA detached primary human colonic epithelial cells. Isolated epithelial cells $\left(5 \times 10^{6} / \mathrm{ml}\right)$ were studied before (0 hours) and after culture (in medium only) for three hours and 24 hours. Cell lysates ( $\square$ ) and supernatants ( 1 ) were subsequently assayed for IL 8 by ELISA. ${ }^{\star} 0$ Hours $\mathrm{v}$ three hours lysate, $p<0 \cdot 01$; three hours $\mathrm{v} 24$ hours supernatant, $p<0.01$.
Interestingly, specimens from one of five subjects did not show any morphological changes despite exposure to high concentrations of toxin A (100 and $1000 \mathrm{ng} / \mathrm{ml}$ for 24 hours). The lack of response to toxin $A$ in these samples could result from the absence of receptors for toxin A. At present there is no information on the nature of such receptors in humans. The lack of such receptors for toxin A on colonic epithelial cells may explain the absence of intestinal disease in some subjects colonised with toxigenic $C$ difficile. ${ }^{26-28}$

In the epithelial cells that do respond to toxin A, cell detachment and subsequent apoptosis could both be specifically mediated by the toxin. Alternatively, apoptosis may represent an inherent response by epithelial cells to detachment from the basement membrane. We therefore performed experiments to discover if primary colonic epithelial cells detached by other means will also undergo apoptosis. In cultures of EDTA detached normal colonocytes, death by apoptosis was seen in many cells over a short time period. It is probable, therefore, that apoptosis of the epithelial cells in response to $C$ difficile toxin A occurs because the cells are denied anchorage to the basement membrane. Such a proposition is supported by recent studies. ${ }^{29-31}$ Cell surface integrin attachment to extracellular matrix is postulated to be important in maintaining cell viability and circumventing the apoptotic response. ${ }^{31}$ Our studies show that such responses are probably operative in the human intestine in vivo.

The mechanism by which $C$ difficile toxin A induces detachment of epithelial cells is unknown. Detachment of the epithelial monolayers could be mediated by proteases secreted by the epithelial cells in response to toxin A. However, culture of the cells in the presence of toxin A and protease inhibitors (phenylmethylsulphonyl fluoride, leupeptin, and pepstatin, individually or in combination) did not inhibit detachment of the epithelial monolayers (unpublished data). A number of studies have shown that the toxin A induced cell rounding is associated with disruption of the actin cytoskeleton. ${ }^{32-34}$ Actin filaments are anchored to cytoplasmic domains of the integrin family of transmembrane proteins by a number of anchoring cytoskeletal proteins. Epithelial cell adhesion to extracellular matrix is mediated by the extracellular domains of integrin molecules. Thus, it can be postulated that disruption of the actin cytoskeleton may affect integrin binding to the extracellular matrix and hence lead to cell detachment.

A consistent finding in our studies was that after detachment from the extracellular matrix, the epithelial cells appeared viable while adherent to one or more cells via cell junctions. In such closely associated cells, an early feature of a cell undergoing apoptosis was the loss of desmosomal plaques (unpublished data). It is not possible from our studies, however, to discover if apoptosis (after detachment from the extracellular matrix) occurs as a consequence of detachment of cells from each other or vice versa. Recent studies support the first rather 
than the second proposal. Loss of adherence between intestinal epithelial cells has been shown to induce apoptosis ${ }^{35}$ and such findings would be consistent with the concept of a requirement for signals from other cells for survival. ${ }^{36}$

It has been suggested that epithelial cells undergo apoptosis to prevent their establishment in an inappropriate position or location. ${ }^{31}$ In addition, apoptosis may allow the injured epithelial cells time to respond by secreting molecules, which will interact with other cells to initiate a systemic protective response. Our finding of induction of IL8 production in the detached colonic epithelial cells before undergoing apoptosis would be consistent with this. Cell death by necrosis, with the early loss of membrane integrity, may not allow the cell to respond in such a manner.

IL8 has recently been shown to be induced in intestinal epithelial cell lines in response to bacterial invasion, ${ }^{37} 38$ or in response to other cytokines such as IL1 and tumour necrosis factor $\alpha .{ }^{39}$ Recently, Gibson and Rosella ${ }^{40}$ have reported induction of IL8 mRNA and protein in normal colonic crypt cells after isolation using collagenase and dispase. Results of our studies support this finding and suggest that IL8 is induced during the process of cell detachment and before death by apoptosis. Normal colonic epithelial cells in vivo do not express IL8. ${ }^{41}$

Thus production of IL8 represents a response of intestinal epithelial cells to a variety of insults or injuries. As IL8 is a very potent chemoattractant for polymorphonuclear cells, such a response may be pivotal in the induction of intestinal inflammation, as occurs in pseudomembranous colitis. Recent studies in animals suggest that the tissue damage and diarrhoea in $C$ difficile colitis are mediated by the polymorphonuclear cells. ${ }^{42}$

In conclusion, the original aim of our studies was to investigate the mechanism by which $C$ difficile toxin $\mathrm{A}$ initiates intestinal disease in humans. The results of these studies, however, have also provided important information on the basic biological responses by epithelial cells to injury in general. As for $C$ difficile, we postulate that toxin $\mathrm{A}$ initiates colonic inflammation in humans by injuring epithelial cells and inducing production of IL8. Detachment of these cells from the basement membrane leads to cell death by apoptosis. IL8 produced by the injured epithelial cells, as well as responses by the exposed lamina propria cells (especially macrophages that lie just below the basement membrane ${ }^{43}$ ), to toxin $A$ and $B$ and other luminal contents would initiate a cascade of events characterised by migration of circulating polymorphonuclear cells into the mucosa to mediate tissue damage and induce diarrhoea.

Most interestingly, our studies suggest that colonic epithelial cells from some adults may be resistant to the effects of even high concentrations of toxin $\mathrm{A}$, possibly explaining why some people are resistant to disease.

This work was supported by the Medical Research Council.

Parts of this study have been presented at meetings of the
British Society of Gastroenterology (Gut 1994; 35 (suppl 5): S38) and American Gastroenterological Association (Gastroenterology 1995; 108: A868).

1 Bartlett JG, Chang TW, Gurwith M, Gorbach SL Onderdonk AB. Antibiotic-associated pseudomembra-
nous colitis due to toxin-producing clostridia. $N$ Engl $f$ nous colitis due to toxin-
Med 1978; 298: 531-4

2 Larson HE, Price AB, Honour P, Borriello SP. Clostridium difficile and the aetiology of pseudomembranous colitis. Lancet 1978; i: 1063-6.

3 Price AB, Davies DR. Pseudomembranous colitis. $f$ Clin Pathol 1977; 30: 1-12.

4 Wren BW. Molecular characterisation of Clostridium diffcile toxin A and B. Rev Med Micro 1992; 3: 21-7.

5 Krivan HC, Clark GF, Smith DF, Wilkins TD. Cell surface binding site for Clostridium difficile enterotoxin: evidence

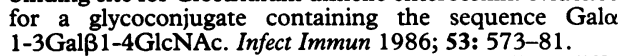

6 Krivan HC, Wilkins TD. Purification of Clostridium difficile toxin A by affinity chromatography on immobilized cile toxin A by affinity chromatography on imm
thyroglobulin. Infect Immun 1987; 55: 1873-7.

7 Tucker KD, Carrig PE, Wilkins TD. Toxin A of Clostridium difficile is a potent cytotoxin. $\mathcal{f}$ Clin Microbiol 1990; 28: 869-71.

8 Mitchell TJ, Ketley JM, Haslam SC, Stephen J, Burdon DW, Candy DCA, et al. Effect of toxin A and B of Clostridium difficile on rabbit ileum and colon. Gut 1986 27: 78-85.

9 Triadafilopoulos G, Pothoulakis C, O'Brien MJ, LaMont TJ. Differential effects of Clostridium difficile toxins A and B on rabbit ileum. Gastroenterology 1987; 93: 273-9.

Lyerly DM, Saum KE, MacDonald DK, Wilkins TD Effects of Clostridium difficile toxins given intragastrically

1 Zweibaum A, Laburthe M, Grasset E, Louvard D. Use of cultured cell lines in studies of intestinal cell differentiation and function. In: Schultz SG, Field M, Rauner BB, eds. Handbook of physiology. Section 6: The Gastrointestinal System. Bethesda, Maryland: American Physiological Society, 1991: 223-55.

12 Madara JL, Dharmsathaphorn K. Occluding junction structure-function relationships in a cultured epithelial monolayer. F Cell Biol 1985; 101: 2124-33.

13 Kamiya S, Reed PJ, Borriello SP. Purification and characterisation of Clostridium difficile toxin A by bovine thyroglobulin affinity chromatography and dissociation in denaturing conditions with or without reduction. $\mathcal{f}$ Med Microbiol 1989; 30: 69-77.

14 Bradford MM. A rapid and sensitive method for the quantitation of microgram quantities of protein utilizing the principle of protein dye binding. Anal Biochem 1976; 72: 248-54.

15 Mosmann T. Rapid colorimetric assay for cellular growth and survival: application to proliferation and cytotoxic assays. F Immunol Methods 1983; 65: 55-63.

16 Mahida YR, Lamming CED, Gallagher A, Hawthorne AB, Hawkey CJ. 5-aminosalicylic acid is a potent inhibitor of interleukin-1 $\beta$ production in organ culture of colonic biopsy specimens from patients with inflammatory bowel disease. Gut 1991; 32: 50-4.

17 Mahida YR, Wu K, Patel S, Jewell DP. Respiratory burst activity of intestinal macrophages in normal and inflammatory bowel disease. Gut 1989; 30: 1362-70.

18 Robinson G, Gray T. Electron microscopy 2. Tissue preparation, sectioning and staining. In: Bancroft JD, Stevens A, eds. Theory and practice of histological techniques. 3rd ed. London: Churchill Livingstone, 1990: 525-62.

19 Savill JS, Wyllie A, Henson JE, Walport MJ, Henson PM, Haslett C. Macrophage phagocytosis of aging neutrophils in inflammation. F Clin Invest 1989; 83: 865-75.

20 Mitchell TJ, Ketley JM, Burdon DW, Candy DCA Stephen J. Biological mode of action of Clostridium difficile toxin A: a novel enterotoxin. $\mathcal{f}$ Med Microbiol 1987; 23: 211-9.

21 Moore $R$, Pothoulakis C, LaMont JT, Carlson S, Madara JL. C difficile toxin A increases intestinal permeability and induces $\mathrm{Cl}^{-}$secretion. Am $\mathcal{F}$ Physiol 1990; 259 (Gastrointest Liver Physiol 22): G165-72.

22 Eglow R, Pothoulakis C, Itzkowits S, Jacobwitz I, O'Keane JC, Gong D, et al. Diminished Clostridium difficile toxin A sensitivity in newborn rabbit ileum is associated with decreased toxin A receptor. F Clin Invest 1992; 90: 822-9.

23 Kerr JFR, Wyllie AH, Currie AR. Apoptosis: a basic biological phenomenon with wide-ranging implications in tissue kinetics. $\mathrm{Br} \mathcal{F}$ Cancer 1972; 26: 239-57.

24 Jacobson MD, Brune JF, King MP, Miyashita T, Reed JC, Raff MC. Bcl-2 blocks apoptosis in cells lacking mitochondrial DNA. Nature 1993; 361: 365-9.

25 Gershenson LE, Rotello RJ. Apoptosis: a different type of cell death. FASEB F 1992; 6: 2450-5.

26 Viscidi R, Willey S, Bartlett JG. Isolation rates and toxigenic potential of Clostridium difficile isolates from various potential of Clostridium difficile isolates from varit

27 Johnson S, Clabots CR, Linn F, Olson MM, Peterson LR, Gerding DN. Nosocomial Clostridium difficile colonisaGerding DN. Nosocomial Clostridium difficil

28 McFarland LV, Mulligan ME, Kwok RYY, Stamm WE. Nosocomial acquisition of Clostridium difficile infection. Nosocomial acquisition of Clostridic

29 Meredith JE, Fazeli B, Schwartz MA. The extracellular matrix as a cell survival factor. Mol Biol Cell 1993; 4: 953-61. 
30 Frisch SM, Francis H. Disruption of epithelial cell-matrix interactions induces apoptosis. F Cell Biol 1994; 124: 619-26.

31 Ruoslahti E, Reed JC. Anchorage dependence, integrins and apoptosis. Cell 1994; 77: 477-8.

32 Hecht G, Pothoulakis C, LaMont JT, Carlson S, Madara JL. C difficile toxin A perturbs cytoskeletal structure and Jight junction permeability of cultured human intestinal tight junction permeability of cultured human intestinal

33 Fiorentini C, Arancia G, Paradisi S, Donelli G, Giuliano $M$, Piemonte $\mathrm{F}$, et al. Effect of Clostridium difficile toxin A and $B$ on cytoskeletal organization in Hep-2 cells: a comparative morphological study. Toxicon 1989; 27: 1209-18.

34 Fiorentini C, Malorni W, Paradisi S, Giuliano M, Mastrantonio P, Donelli G. Interaction of Clostridium difficile toxin A with cultured cells: cytoskeletal changes and nuclear polarization. Infect Immun 1990; 58: 2329-36.

35 Bates RC, Buret A, van Helden DF, Horton MA, Burns GF. Apoptosis induced by inhibition of intercellular contact. $\mathcal{F}$ Cell Biol 1994; 125: 403-15.

36 Raff MC. Social controls on cell survival and cell death. Nature 1992; 356: 397-400.

37 Eckmann L, Kagnoff MF, Fierer J. Epithelial cells secrete the chemokine interleukin- 8 in response to bacterial entry. Infect Immun 1993; 61: 4569-74.
38 McCormick BA, Colgan SP, Delp-Archer C, Miller SI, Madara JL. Salmonella typhimurium attachment to human intestinal epithelial monolayers: transcellular signalling to subepithelial neutrophils. $\mathcal{f}$ Cell Biol 1993; 123: 895-907.

39 Eckmann L, Jung HC, Maly CS, Panja A, Wroblewska EM, Kagnoff MF. Differential cytokine expression by human intestinal epithelial cell lines: regulated expression of intestinal epithelial cell lines: regulated expression

40 Gibson P, Rosella O. Interleukin 8 secretion by colonic crypt cells in vitro: response to injury suppressed by butyrate and enhanced in inflammatory bowel disease. Gut 1995; 37: 536-43.

41 Daig R, Andus T, Aschenbrenner E, Rath H, Falk W, Scholmerich J, Gross V. Detection of interleukin-8 mRNA in mucosal mononuclear cells of patients with inflammatory bowel disease by in situ hybridization. Gastroenterology 1994; 106: A669.

42 Kelly CP, Becker S, Linevsky JK, Joshi MA, O'Keane JC, Dickey BF, et al. Neutrophil recruitment in Clostridium difficile toxin A enteritis in the rabbit. $\mathcal{F}$ Clin Invest 1994; 93: $1257-65$.

43 Mahida YR, Patel S, Gionchetti P, Vaux D, Jewell DP. Macrophage sub-populations in lamina propria of normal and inflamed colon and terminal ileum. Gut 1989; 30: 826-34. 